\title{
A Case for the Development of Family Practice Rural Training Tracks
}

\author{
James R. Damos, MD, Carrol Christman, MA, Craig L. Gjerde, PbD, Jobn Beasley, MD, \\ Maggie Schutz, RN, MS, and Mary Betb Plane, PbD
}

Enthusiasm for alternate training sites has been strong among practicing family physicians and students seeking family practice residency positions in Wisconsin. The number of rural training tracks in the state is increasing rapidly. The University of Wisconsin currently has 4 residents in two rural training tracks. If 1998 recruitment is successful, there will be 12 residents in seven rural training tracks operated by two sponsoring institutions in the state. The Wisconsin rural training tracks are 1-2 programs, ${ }^{1}$ in which the family practice resident spends the first year in the urban medical center of the home program completing appropriate rotations, such as internal medicine, pediatrics, obstetrics-gynecology, emergency medicine, surgery, and critical care, and the last 2 years in a rural community and rural hospital as an apprentice with a family practice group. During the last 2 years, the resident can receive longitudinal training in specialty areas with visiting subspecialists and can spend time away from the rural medical practice for specialty rotations not available in the rural setting.

The development of the Wisconsin rural training tracks was based in part on the pioneering work of Rosenthal et al. ${ }^{2}$ The process used to develop the first rural training track was adopted as a template for developing other rural training tracks in Wisconsin and in other states. ${ }^{3}$ Not much has been published, however, assessing educational outcomes and documenting the effects of rural training tracks on communities. Despite this lack of documentation, we believe rural tracks have merit as a training model for family practice and

Submitted, revised, 12 November 1997.

From the Department of Family Medicine, University of Wisconsin Medical School, Madison. Address reprint requests to James R. Damos, MD, Department of Family Medicine, University of Wisconsin Medical School, 777 South Mills St, Madison, WI 53715. they should continue to be developed and studied for the following reasons:

\section{Rationale for Rural Training Tracks}

Family Physicians Are Urgently Needed to Provide Comprebensive Medical Services in Rural Areas

Compared with 9 percent of urban residents, 29 percent of rural residents of the United States live in areas with a shortage of health professionals. ${ }^{4}$ Both the Council on Graduate Medical Education (COGME) and the American Academy of Family Physicians have recommended increasing the number of family physicians, in part, to meet the needs of rural and underserved areas. COGME also noted that while there are sufficient numbers of physicians, many generalists and specialists remain largely regionalized to urban and metropoli$\tan$ centers.

An article in a recent American Family Physician newsletter ${ }^{5}$ comments on maldistribution even within family medicine:

Family medicine has provided thousands of physicians to underserved rural communities over the years. In recent years the number choosing rural practice have remained at about 600 per year, despite increases in residencies and resident positions. Family practice is now in danger of becoming much like the other medical specialties: as the supply increases, there is increasing maldistribution of the specialty. The only exception to this rule is urban poverty practice where family practice graduates have posted major increases. If family medicine fails to address this location issue, it will soon face more than threats to Title VII funding. Without special efforts to increase the numbers of family medicine residents choosing rural locations, much of the political power of the specialty will be lost. This could have impacts on graduate medical education funds at the federal and state levels. 
We contend that family medicine must not only see as its mission the need to encourage graduates to select rural practice, but it must also be prepared to provide the needed comprehensive services. Maternity care, care of the elderly, and emergency care are essential services that are often inadequately available in rural areas.

In counties with populations of fewer than 10,000 , less than 1 percent of the physicians are obstetricians. ${ }^{6}$ With obstetricians largely regionalized near urban or teaching centers, the provision of maternity care in rural communities is essentially the responsibility of family physicians and certified nurse midwives. Two thirds of women giving birth in rural communities are attended by family physicians or general practitioners. ${ }^{7} \mathrm{Na}$ tionally, however, the number of family physicians providing maternity care has been dropping for a variety of reasons (malpractice, lifestyle, struggles getting privileges in hospital maternity care units, lack of role models during residency training, and fear of emergencies that can develop even in lowrisk deliveries). ${ }^{8-11}$

The declining role of the family physician in maternity care is having an impact on access to maternity care in rural communities. Larimore and Davis ${ }^{12}$ have shown that declining access to maternity care in rural areas affected the ability of Florida to reduce its infant mortality rate. Allen and Kamradt ${ }^{13}$ suggested that decreased access to maternity care in rural areas of Indiana resulted in an increase in infant mortality. Nesbitt et al ${ }^{14}$ found that maternity patients who must travel from rural areas to regionalized perinatal centers for prenatal care and delivery have more complicated deliveries, higher rates of prematurity, and higher costs of neonatal care.

Family physicians and general internists provide the majority of primary care services to the home-dwelling elderly and nursing home residents in rural communities. Many rural elderly are unwilling or unable to travel to urban areas to see a variety of subspecialists for their multiple medical problems. The elderly population is growing at a pace greater than that of the general population. ${ }^{15,16}$ Currently 1.5 million Americans live in nursing homes; by the year 2030, this number could increase to 5 million. ${ }^{17-19}$ Rural elderly represent a large population that is particularly vulnerable to health care provider shortages.

To save lives, rural hospital emergency depart-
Table 1. Relation Between the Length of Rural Training and Rural Practice Choice.

\begin{tabular}{ccc}
$\begin{array}{c}\text { Number of } \\
\text { Required } \\
\text { Rural Months }\end{array}$ & $\begin{array}{c}\text { Programs with } \\
\text { Rural Months, } \\
\text { No. }\end{array}$ & $\begin{array}{c}\text { Graduates } \\
\text { Choosing Rural } \\
\text { Practice, \% }\end{array}$ \\
\hline 0 & 212 & 24.4 \\
1 & 82 & 36.5 \\
2 & 29 & 45.6 \\
3 & 15 & 52.3 \\
$4-6$ & 4 & 51.0 \\
$22+$ & 11 & 68.5 \\
\hline
\end{tabular}

ments must be able to manage the first hour of trauma or critical care before transfer can be made to a higher level center. Many rural family physicians have completed emergency advanced life support courses (advanced cardiac life support, advanced trauma life support, pediatric advanced life support, advanced life support in obstetrics) and routinely provide emergency services when residency-trained emergency physicians are not available. In reality, even when board-certified emergency physicians are available at a rural hospital, family physicians are called in to assist with major trauma when many victims are involved.

\section{Length and Content of Training Appear to Be Related to Choice of Rural Practice}

Many family practice residencies offer residents a brief exposure to a rural family practice career through rural rotations. A short exposure might not be enough. Bowman ${ }^{20}$ found that the more time family practice residents were required to spend in rural communities with rural physicians, the higher the likelihood of the residents choosing rural practice (Table 1). Their national survey of rural family physicians found that 31.5 percent took a required rural rotation during residency and 48.5 percent took an elective rural residency month. The same study showed that the more maternity care training a family practice resident had, the more likely he or she was to choose rural practice (Table 2).

\section{Residents Tend to Settle Where They Train}

Magnus and Tollan ${ }^{21}$ reported that the establishment of a new medical school in northern Norway had a beneficial effect with 56 percent of the graduates remaining in remote northern areas. Lebel and $\operatorname{Hogg}^{22}$ showed that community-based residents in Ottawa were more likely to choose a 
Table 2. Relation Between the Length of Obstetrics Training and Rural Practice Choice.

\begin{tabular}{ccc}
$\begin{array}{c}\text { Number of } \\
\text { Obstetric } \\
\text { Rural Months }\end{array}$ & $\begin{array}{c}\text { Number of } \\
\text { Programs }\end{array}$ & $\begin{array}{c}\text { Graduates } \\
\text { Choosing Rural } \\
\text { Practice, \% }\end{array}$ \\
\hline 2 & 14 & 23.8 \\
3 & 11 & 31.2 \\
4 & 71 & 34.1 \\
$5+$ & 30 & 42.1 \\
\hline
\end{tabular}

small community practice, and LeFevre and Colwill ${ }^{23}$ found that residency location had an effect on practice location.

The experience of the University of Wisconsin family practice residency programs indicates that residency location is a strong determinant for graduate practice location. Dots representing all program graduates in Wisconsin (Figure 1) show clusters of graduates around the residency training sites. We speculate that if more training is moved to rural tracks, the same factors that encourage residents to practice near their urban residency sites will lead them to practice near their rural residency sites as well as in other rural sites. Bowman $^{20,24}$ recommends rural tracks as one strategy for increasing rural practice selection based on evidence from the Society of Teachers of Family Medicine study.

\section{Urban Residency Programs Where Graduates Locate} Might Have Difficulty Providing Sufficient Patient Care Experience for Residents

The history of subspecialization offers a warning. Until the 1950s, most US physicians were general practitioners who had 1 year of postgraduate training (rotating internship). In the 1950s and 1960s, the National Institutes of Health began to offer research fellowships to attract young physicians into academic research. ${ }^{25}$ By the $1970 \mathrm{~s}$, research fellowships became clinical fellowships and further evolved into subspecialty residency positions that were supported by Medicare or hospital funds. Hospitals found that subspecialty residents were essential because they could perform a wide variety of procedures and provide both care for hospitalized patients and service to the hospital.

The increased number of subspecialists graduating from university hospital fellowships prompted community hospitals to add subspecialists to their staffs. As these graduates began to care for patients in the same communities served by the university hospitals, the number of patients needing attention at the university hospitals declined, and many university hospitals began to struggle for patient referrals.

Likewise, family practice training programs might also see their clinic patient populations decline in urban areas as their graduates enter practice in nearby communities. Continuous patient care with a stable panel of patients is a basic requirement for family practice training and program accreditation. Although rural tracks are not the only option for providing residents with access to stable patient populations, such programs move residents into settings that can provide equivalent or better training while taking the pressure off urban programs.

\section{Rural Family Physicians and Their Practices Are Well Suited to Prepare Residents for Rural Practice}

Academic medical centers that require tenure pressure family practice faculty to develop a research focus, obtain grant support, and publish in peer-reviewed journals. Academic development, however, can come at the expense of maintaining the wide range of clinical skills essential to rural family practice; university-based family practice faculty might drop maternity care, critical care, or procedures common to rural family practice to focus on teaching and research in a limited area. These limitations can result in fewer comprehensive practice role models for residents interested in rural practice, where a broad set of clinical practice skills is needed (maternity care, emergency care, care of adults, care of the elderly, care of children and adolescents).

Observing rural physicians successfully provide maternity care can be a great encouragement to residents. In a 1991 survey, University of Wisconsin family practice graduates suggested that to keep maternity care a strong part of family practice, residents should be ensured the positive experience of working with skilled, confident family physician role models. ${ }^{26}$ Graduates recommended avoiding training by nonsupportive obstetricians, even if it meant training in a community outside the program where family physicians routinely provide maternity care and work collaboratively with obstetricians.

Smith and Howard ${ }^{27}$ reported that factors positively associated with providing maternity care were (1) practicing in a rural community and (2) 
Figure 1. Locations of University of Wisconsin family practice residency graduates (1973-1996) practicing in Wisconsin.

\begin{tabular}{lcc}
\hline Program & $\begin{array}{c}\text { Total } \\
\text { Graduates } \\
\text { No. }\end{array}$ & $\begin{array}{c}\text { Graduates } \\
\text { in Wisconsin* } \\
\text { No.(\%) }\end{array}$ \\
\hline Appleton & 87 & $53(61)$ \\
Eau Claire & 109 & $68(62)$ \\
Madison & 289 & $149(52)$ \\
Milwaukee & 129 & $73(57)$ \\
Wausau & 88 & $57(65)$
\end{tabular}

${ }^{*}$ Confirmed number, $10-15 \%$ might be lost to follow-up. Note: each dot $=1$ graduate.
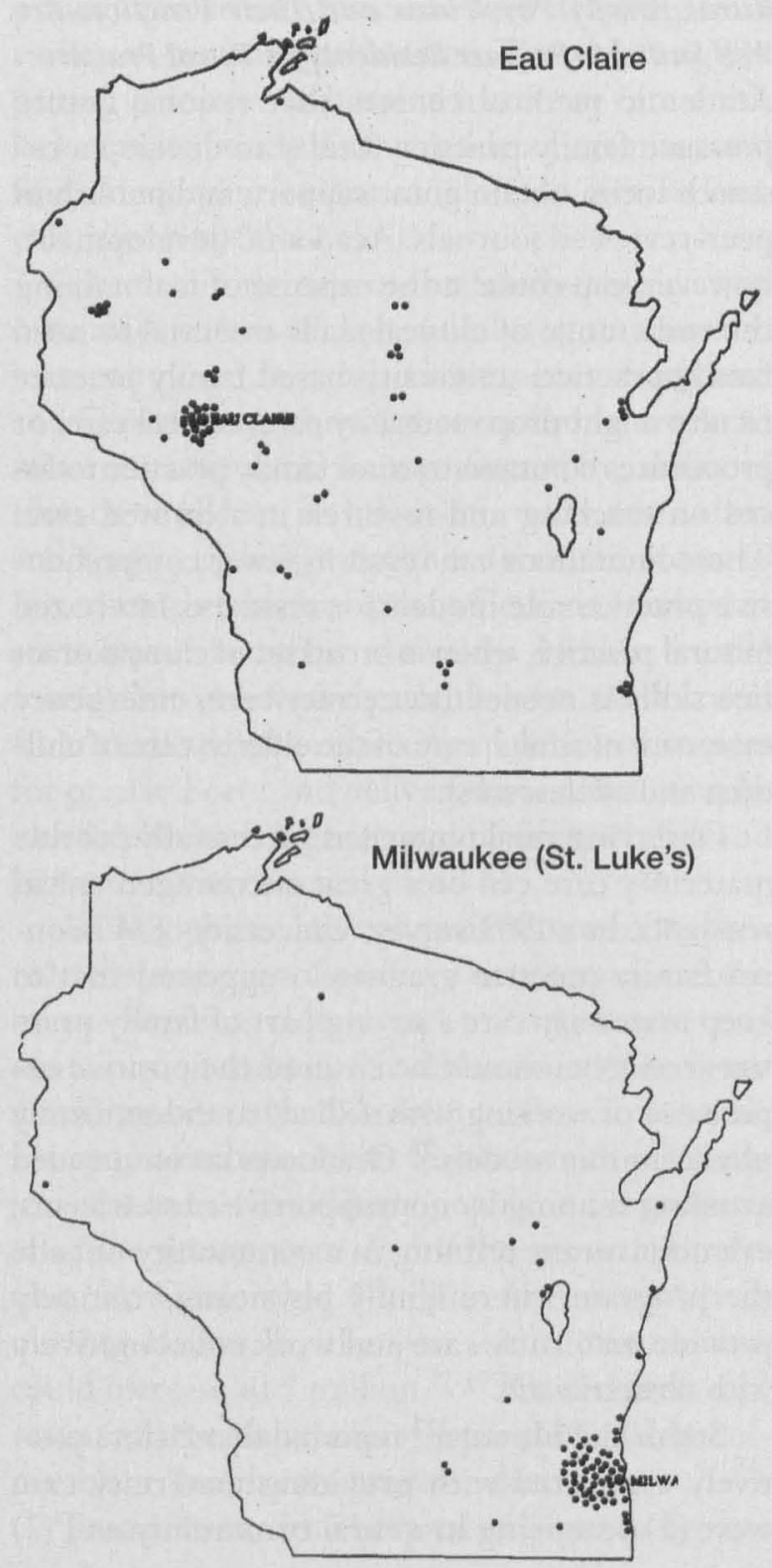
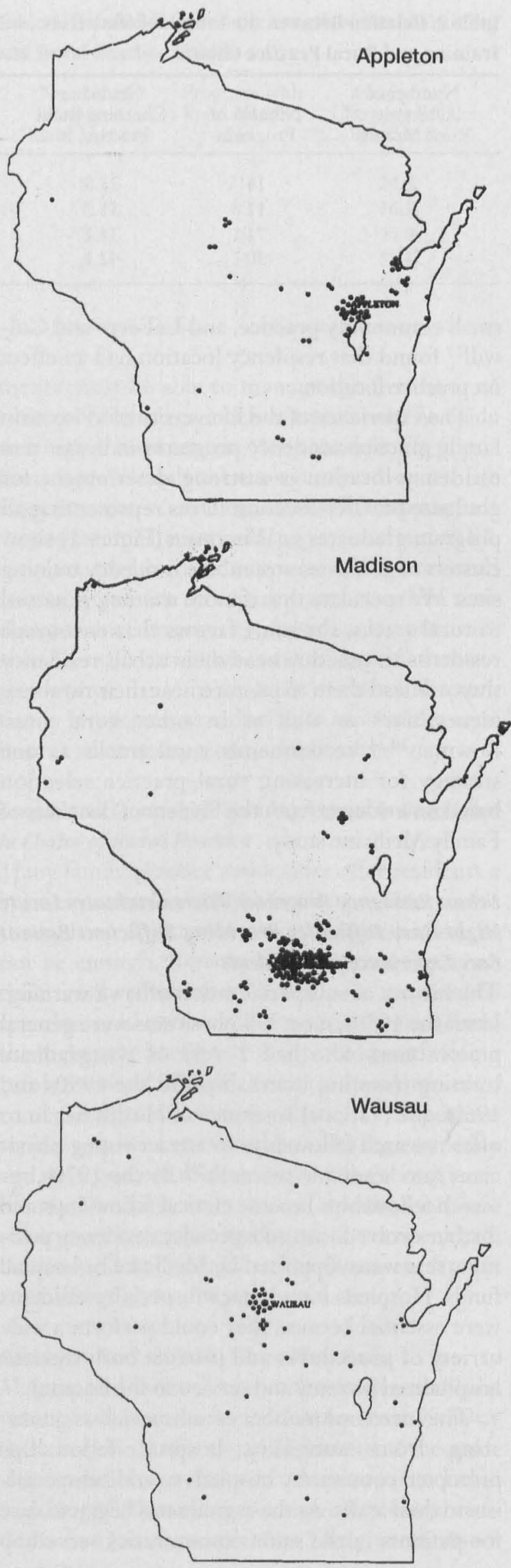
being exposed to good family physician role models during training; they found that graduates who felt inadequately trained in maternity care chose not to provide maternity care and were more likely to go into urban practices. The nursing literature is replete with the value of mentors as role models in training. ${ }^{28,29}$ A national survey by Sakornbut and Dickinson ${ }^{30}$ illustrated that supervision of obstetric care by family practice faculty increased threeto four-fold the likelihood that family practice residents will choose to do obstetrics.

The lack of immediate on-site specialty backup in rural areas should be seen as a challenge rather than as a threat to the aspiring rural family physician. In larger urban teaching centers, an abundance of subspecialists are available for immediate consultation for neonatal resuscitation, delivery room emergencies, and trauma and cardiac emergencies. In some cities, family practice residents are told by subspecialists and even by some academic family physician teachers that they should not be performing certain procedures common to rural practice. Because referral is the accepted standard of care in university settings, family physician faculty might be more likely to refer patients who would normally be cared for by family physicians in rural settings. As a result, urban family practice residents can learn a sense of helplessness when encountering delivery room emergencies (retained placenta, postpartum hemorrhage, instrument delivery) and neonatal emergencies (resuscitation, sepsis evaluation, hypoglycemia, tachypnea) and miss the opportunity to acquire the breadth of skills needed in rural practice.

Other rapidly evolving changes in urban health care systems further highlight differences in urban and rural practice. In some large university programs, the combination of managed care, numerous clinical sites, heavy reliance on Medicare funds passed through hospitals, and multiple duties of academic faculty require complex, multiclinic after-hours call systems quite different from systems encountered in rural practice. The evolution of a hospitalist model, in which family physicians care for outpatients and subspecialists care for inpatients, is also gaining momentum in some larger urban areas. How will family physicians receive training relevant to rural family practice if changes such as these become the norm?

Our rural family physician colleagues and the environment in which they practice can be much better positioned to serve the family practice resident interested in a rural career.

\section{Rural Training Tracks Offer Advantages for} Residents, Academic Faculty, and Rural Pbysicians

Family practice residents are exposed to many advantages when they receive training in a rural community. Fewer primary care residents and very likely no subspecialty residents compete for patient care experience. Faculty role models perform procedures common to rural practice. Residents can experience being part of a community where all members of a family seek care from the family physician for most of their health care needs. For residents considering rural practice, this type of preparation is vital. For those who ultimately choose urban practice, the experience will be no less valuable because it exposes the resident to the essence of family practice.

The nonclinical aspects of training in a rural community can also be enlightening. Residents can participate in community activities and experience the effects of their medical practice as they interact with patients as neighbors and citizens. A resident's spouse and family members can experience rural life first hand.

Students applying to the University of Wisconsin family practice rural training tracks say they look forward to a great deal of experiential learning, believe they will receive more personalized teaching, and sense they will be welcomed and needed by the rural practice. Students realize that to achieve these benefits, they must be committed to living in the rural area for the last 2 years of their training.

Rural physicians gain the following benefits from rural training tracks: (1) clinical assistance in their practice, (2) increased career satisfaction, (3) improved image both locally and at the academic medical center, (4) increased collaborative linkages to academic medical centers, and (5) increased attractiveness of the practice to physicians being recruited.

Rural training builds relations between academic and rural physicians that can benefit all parties. Rural physicians can learn teaching skills from experienced academic family physician teachers through faculty development programs. Academic family physicians can broaden their horizons by observing clinicians skilled in rural medicine practice case management. Town-gown 
rivalries that might exist can be bridged by having urban and rural physicians work together on educational ventures to improve access to health care in rural communities.

\section{Rural Training Track Weaknesses}

Despite many good arguments for developing rural training tracks, there are drawbacks. Administrative and teaching time, program cost, practice volatility, distance, isolation, quality, and accreditation requirements are serious concerns. Many programs (and rural clinics) interested in developing a rural track have neither the time nor the staff for the enormous amount of preplanning required to prepare the site, write the accreditation documents, negotiate affiliation agreements, facilitate site visits by the American College of Graduate Medical Education (ACGME), write recruitment materials, and train the rural faculty. It could be difficult to recruit and maintain the number of residents required by the ACGME-at least 2 residents per site, 1 second-year resident and 1 thirdyear resident-to increase collegial support.

Smaller training sites are also more vulnerable to staff changes. Should one or more physicians leave the practice suddenly, inadequate teaching time could result as the remaining physicians struggle to care for the patients who visit the clinic. What should be a positive experience could turn out to be negative for residents if they work with exhausted, stressed role models. Distances that need to be traveled by residents pose driving dangers and weather hazards. Residents can feel isolated from the colleagues they trained with during their first year. The quality of education residents receive in rural tracks might be questioned until sufficient learning outcomes research shows the effectiveness of this educational model. Such problems are not unique to rural tracks, but they might have to be addressed differently than they are in the larger urban programs.

\section{Rural Tracks Alone Will Not Solve Rural Pbysician Shortages}

Many additional changes in the health care system are necessary to enhance rural health. Typically, Medicare pays health maintenance organizations 18 percent more to care for urban enrollees compared with rural enrollees. ${ }^{31}$ Medicare must recognize the contributions of rural providers and compensate them equally. The American College of Physicians has recommended remote access telecommunication and innovative delivery systems to improve access to and delivery of primary care in rural areas. ${ }^{32}$

Finally, it is up to the rural medical communities that remain underserved at the end of the 20 th century to persuade graduates to consider staying in rural areas, find satisfying practices, and provide the services needed. Rural physicians must contribute to collegial partnerships with academic physicians, teach clinical skills, and share their enthusiasm for rural practice. Community members must help residents integrate into the social community.

\section{Conclusions}

Academic and practicing family physicians must work together to correct physician maldistribution and assure access to medical care in rural areas. There is beginning evidence to suggest that rural training tracks are able to produce graduates who enter rural practice. A recent survey by Rosenthal et al ${ }^{33}$ showed that 76 percent of graduates of one-two rural residency tracks entered rural practice after graduation. Further studies are needed to determine whether rural track residents are as well prepared as their core program colleagues and whether rural training tracks are an equivalent or preferred method of preparing residents for rural practice. Broad qualitative studies can measure the costs and effects of rural training on community physicians, community hospitals, and the community itself. If evaluation results show that the effort is worth the outcome, traditional models of residency training should be modified to include more rural training options.

\section{References}

1. Program information form for residencies in family practice. Chicago: Accreditation Council for Graduate Medical Education, 1997:iii.

2. Rosenthal TC, Maudlin RK, Sitorius M, Florence JA, Markowski G, Cleveland PD, et al. Rural training tracks in four family practice residencies. Acad Med 1992;67:685-91.

3. Damos JR, Sanner LA, Christman C, Aronson J, Larson S. A process for developing a rural training track. Fam Med 1998;30:94-9.

4. Dalen JE, editor. US physician manpower needs: generalists and specialists: achieving the balance. Arch Intern Med 1996;156:21-24.

5. STFM Group on Rural Health. Concerns raised re- 
garding graduate locations. Am Fam Physician Newslett, Summer 1997.

6. Kindig DA, Movassaghi $H$. The adequacy of physician supply in small rural counties. Health Aff Millwood 1989;8(2):63-76.

7. Institute of Medicine. Medical professional liability and the delivery of obstetric care. Washington, DC: National Academy of Press, 1989.

8. Larimore WL. Pregnancy care liability misperceptions among medical students in Florida. Fam Med 1994;26:154-6.

9. Greenberg DM, Hochheiser LI. Family practice residents' decision making regarding future practice of obstetrics. J Am Board Fam Pract 1994;7:25-30.

10. Nesbitt TS, Arevalo JA, Tanji JL, Morgan WA, Aved B. Will family physicians really return to obstetrics if malpractice insurance premiums decline? $\mathrm{J}$ Am Board Fam Pract 1992;5:413-8.

11. Nesbitt TS, Kahn NB, Tanji JL, Scherger JE. Factors influencing family physicians to continue providing obstetric care. West J Med 1992;157:44-7.

12. Larimore WL, Davis A. Relation of infant mortality to the availability of maternity care in rural Florida.J Am Board Fam Pract 1995;8:392-9.

13. Allen DI, Kamradt JM. Relationship of infant mortality to the availability of obstetrical care in Indiana. J Fam Pract 1991;33:609-13.

14. Nesbitt TS, Connel FA, Hart LG, Rosenblatt RA. Access to obstetric care in rural areas: effect on birth outcomes. Am J Public Health 1990;80:814-8.

15. Clifford WB, Lilley SC. Rural elderly: their demographic characteristics. In: Bull CN. Aging in rural America. Focus Editions Ser Vol 162. Newbury Park, Calif: Sage Publications, 1993:3-20.

16. Fuguitt GV, Beale CL. The changing concentration of the older nonmetropolitan population, 1960-90.J Gerontol 1993;48:S278-88.

17. Zedlewski SR, Narnes RO, Burt MK, McBride TD, Meyer J. The needs of the elderly in the 21 st century. Washington, DC: The Urban Institute, 1989.

18. Doty PJ. The oldest old and the use of institutional long term care from an international perspective. In: Suzman RM, Willis DP, Manton KG, editors. The oldest old. New York: Oxford University Press, 1992:251-67.

19. Besdine RW, Rubenstein LZ, Snyder L, editors. Medical care of the nursing home resident: what physicians need to know. Philadelphia, American College of Physicians, 1996:xiii.

20. Bowman RC, Penrod JD. Family practice residency programs and the graduation of rural family physicians. Fam Med 1998;30:288-92.

21. Mangus JH, Tollan A. Rural doctor recruitment: does medical education in rural districts recruit doctors to rural areas? Med Educ 1993;27:250-3.

22. Lebel D, Hogg W. Effect of location on family medicine residents' training. Can Fam Physician 1993; 39:1066-9.

23. LeFevre ML, Colwill JM. Practice location as a function of medical school and residency location: implications for resident selection. J Fam Pract 1983;16:1157-60.

24. Bowman RC. Continuing family medicine's unique contribution to rural health care. Am Fam Physician 1996;54:471-4, 479, 483.

25. Dalen JE. US physician manpower needs. Generalists and specialists: achieving the balance. Arch Intern Med 1996;156:21-4.

26. Turkal N, Christman C. Graduates' comment on issues related to the decline of Wisconsin family physicians providing maternity care. Wis Med J 1996;95:17-21.

27. Smith MA, Howard KP: Choosing to do obstetrics in practice: factors affecting the decisions of third-year family practice residents. Fam Med 1987;19:191-4.

28. Hayes E. Helping preceptors mentor the next generation of nurse practitioners. Nurse Pract 1994; 19(6):62-6.

29. Taylor LJ. A survey of mentor relationships in academe. J Prof Nurs 1992;8(1):48-55.

30. Sakornbut EL, Dickinson L. Obstetric care in family practice residencies: a national survey. J Am Board Fam Pract 1993;6:379-84.

31. United States, Prospective Payment Assessment Commission. Medicare and the American health care system: report to the Congress. Medicare and Medicaid guide, issue no 964, no 960, part 2. Washington DC: The Commission, 1997.

32. Rural primary care. American College of Physicians. Ann Intern Med 1995;122:380-90.

33. Rosenthal TC, McGuigan MH, Osborne J, Holden DM, Parsons MA. One-two residency tracks in family practice: are they getting the job done? Fam Med 1998;30:90-3. 